American Journal of Pharmaceutical Education 2017; 81 (3) Article 48.

\title{
RESEARCH
}

\section{Effect of a Dedicated Pharmacy Student Summer Research Program on Publication Rate}

\author{
Katharina Brandl, PhD, ${ }^{\mathrm{a}}$ David Adler, PharmD, ${ }^{\mathrm{a}}$ Carolyn Kelly, MD, ${ }^{\mathrm{a}}$ Palmer Taylor, $\mathrm{PhD},{ }^{\mathrm{a}}$ \\ Brookie M. Best, PharmD ${ }^{\mathrm{a}, \mathrm{b}}$ \\ ${ }^{a}$ University of California San Diego, La Jolla, California \\ ${ }^{\mathrm{b}}$ University of California San Diego-Rady Children's Hospital San Diego, La Jolla, California \\ Submitted October 27, 2015; accepted February 3, 2016; published April 2017.
}

\begin{abstract}
Objectives. This study investigated the impact of an optional 12-week summer research program on the publication outcomes and satisfaction with the required research projects of doctor of pharmacy (PharmD) students at the Skaggs School of Pharmacy and Pharmaceutical Sciences (SSPPS) at the University of California San Diego.

Methods. PubMed and Google searches provided student publications, and satisfaction surveys submitted by students provided their perceptions of the research project value.

Results. Of the studied cohort, the 130 students who fulfilled the requirement through the optional summer research program provided 61 full-text manuscripts and 113 abstracts. The 305 students who chose the standard pathway provided 35 full-text manuscripts and 34 abstracts. Students in both pathways agreed or strongly agreed that the research project was a valuable experience.

Conclusions. The 12-week intensive summer research program improved the publication rate of pharmacy students and provided a high overall satisfaction with this independent learning experience.

Keywords: research project, doctor of pharmacy degree, curriculum, publication rate, education
\end{abstract}

\section{INTRODUCTION}

The Accreditation Council for Pharmacy Education (ACPE) recognizes the benefit to pharmacy students of mastering scientific method and learning research design by requiring instruction in several research-related topics within the doctor of pharmacy (PharmD) curriculum. ${ }^{1}$ Courses in biostatistics, drug information, and research design facilitate these competencies, fostering critical and analytical thinking, and life-long learning skills in pharmacy students.

Although ACPE does not require the actual research project, approximately $25 \%$ of US pharmacy schools have implemented a hands-on research project in recognition of the added benefits of such a requirement. ${ }^{2-5}$ Completing a research project promotes expertise in areas of problem solving, interprofessional collaboration, and leadership as required by $\mathrm{ACPE},{ }^{1}$ as well as providing direct experience for students with a research-related career goal.

Conducting research and completing a research project require generating a hypothesis, performing systematic literature review, developing study methods, and

Corresponding Author: Katharina Brandl, Skaggs School of Pharmacy and Pharmaceutical Sciences, University of California San Diego, 9500 Gilman Drive (MC-0675), La Jolla, CA 92093-0675. Tel: 858-822-6853. E-mail: kbrandl@ucsd.edu collecting and analyzing data. These promote higher-order learning by requiring all elements of Bloom's taxonomy: remembering, understanding, applying, analyzing, evaluating, and the creation of new knowledge. ${ }^{6}$ Whereas the overall curriculum emphasizes learning in breadth, a research project facilitates learning in depth and provides opportunities for independence not offered in a standardized curriculum. These opportunities to develop self-directed learning skills and problem solving promote life-long learning, which will benefit the student in his or her future career as a pharmacist. Presentations of research project study findings through manuscripts and in meetings provide a valuable venue to practice and demonstrate accomplishments in interprofessional collaboration and leadership as require by ACPE. All of the above elements may be introduced through research-related course work, but independent projects provide unique opportunities for students to practice and master these skills.

Given the growing recognition of the importance of an independent research project in a PharmD curriculum, investigating the value of a summer research program to increase the benefits of the research project requirement becomes relevant. Since its inception in 2002, SSPPS has included an independent research project as a requirement for graduation. Although many pharmacy schools conduct 


\section{American Journal of Pharmaceutical Education 2017; 81 (3) Article 48.}

their research project during year three or year four of the curriculum, ${ }^{7,8}$ students at SSPPS may start their research project at any time during pharmacy school. Students are generally encouraged to start early during their graduate education to allow adequate time for an in-depth and sustained research experience. The time spent to fulfill the research requirement varies significantly between students, but all students must meet the completion requirements of a minimum of 120 hours spent on research activities; a final drafted manuscript; and formal presentation of a poster at an internal (SSPPS) venue.

In 2006, SSPPS implemented a summer research program as an optional opportunity for students to gain a more in-depth and intensive research experience. Summer research students perform an individual mentored research project full-time (40 hours per week) for 12 weeks over the summer after the first or second year of pharmacy school. Before beginning the summer research program, students have completed the clinical research design and applications course required during year one of the SSPPS curriculum. Students learn to formulate a research question and design a clinical study. In addition, they are informed about ethical issues associated with conducting research projects and undergo human subjects research training. A biostatistics course (also required during year one) equips them with concepts in order to apply the proper statistical methods relevant to their project. Furthermore, in a required drug information course, students learn how to critically evaluate published literature. No other prerequisites are necessary to enter the summer research program. However, the mentor, can seek a student with required skills (eg, laboratory experience) if needed for the project. The student receives a stipend to help offset living expenses at the current National Institutes of Health (NIH) pre-doctoral stipend level.

As the "gold standard" of academic success, ${ }^{9}$ publication rates from students in the summer research program were determined for the past eight years and compared with publication rates resulting from the standard required research projects of SSPPS pharmacy students who did not participate in the summer research program. In addition, students' satisfaction in the two different research experiences were examined over the past two years. The outcomes of this study can act as reference for other pharmacy schools exploring the design and implementation of a required research project or optional intensive research opportunities in their curriculum.

\section{METHODS}

Each pharmacy student at SSPPS must complete a research project related to any area of pharmacy or pharmaceutical sciences. The project must include at least 120 hours and be supervised by a project adviser who is a faculty member from SSPPS or UC San Diego School of Medicine, or is one of a variety of other health sciences professionals. Depending on the nature of the project, students may work independently or in groups up to a maximum of 4 students. Each student must submit a final written manuscript of their completed project to the research project director and present a poster at an SSPPS annual poster session just prior to graduation. The manuscript is for internal use only and does not have to be submitted for publication in a journal related to the disciplines of pharmacy.

Traditional pathway for completing the research project: Students are encouraged to consider potential projects beginning in their first year and submit a research proposal to the research project director, but they are allowed to complete their research project in any academic year.

Summer Research Program: Students applying to the summer research program must submit a proposal packet including a research proposal, the curriculum vitae of the student and the mentor, a mentor letter of support, and any required institutional approvals. Each student must submit his/her own individual research proposal and obtain IRB or approval to use animals if applicable. A minimum of 480 hours is required to conduct the actual research answering his/her own specific research question.

However, students may work within the same overall large research goal as long as each student works on a separate aim. Each student must submit an abstract summarizing the project results to the summer research program director and present a poster at an annual health sciences summer research poster session including both medical and pharmacy students at UC San Diego. To fulfill the SSPPS curricular research requirement, students also must submit a final written manuscript of their completed project to the research project director as described above. Each student in the summer research program receives a stipend set at the current NIH predoctoral level for 3 months of support.

PubMed and Google searches identified publications resulting from the research projects. The students' and preceptors' last names and the initials of his/her first name were used to search PubMed. The last and first name of the student were used to search Google, followed by a key term of the research project to narrow down the results. Identified publications were assigned one of the two following categories: publication as a full-text manuscript (including original research articles, book chapters, editorials, and reviews) or publication as an abstract (poster presentation or podium presentation at an external [nonUC San Diego] professional conference). Internally 


\section{American Journal of Pharmaceutical Education 2017; 81 (3) Article 48.}

presented abstracts were excluded from analysis. Publications that resulted from a subsequent residency or $\mathrm{PhD}$ program (even with same mentor) or from work prior to the SSPPS research project were not included in the analysis. The searches of PubMed and Google were conducted during August 2015.

After the completion of the research project, a series of 12 statements on a 5-point Likert scale ranging from strongly disagree to strongly agree provided feedback from students. These statements focused on the project experience, the project adviser, the preparedness in conducting research, and the skills acquired through the research experience. Responses were de-identified and analyzed. An exemption was obtained from the institutional review board of the University of California San Diego for data analysis.

Publications and evaluations were compared between two non-overlapping groups - students who participated in the summer research program and those who did not. The significance of the number of publications (published full-text manuscripts and abstracts) by each group was analyzed using the Fisher exact test and the twoproportion $\mathrm{Z}$ test. Two-tailed tests were used with significance set at $p<0.05$. Students' satisfaction were analyzed using the Mann-Whitney U test.

\section{RESULTS}

Because SSPPS enrolls approximately 60 students per class, about 120 first- and second-year pharmacy students are eligible to apply for the summer research program each summer. A total of 130 pharmacy students participated in the summer research program; the number from each graduating class was 4 for the class of 2008, 8 for the class of 2009, 4 for the class of 2010, 16 for the class of 2011, 14 for the class of 2012, 23 for the class of 2013, 32 for the class of 2014, and 29 for the class of 2015.

A total of 435 pharmacy students completed their research project from the graduating classes of 2008 through 2015. During the past eight years, 130 students completed research projects in the summer research program, and 305 students did not participate in the summer research program and completed their research project at any time during the curriculum. As one measure of academic success of the summer research program, publication rate was determined. A total of 174 publications (61 full-text manuscripts and 113 abstracts) were identified to result from students participating in the summer research program (Figure 1). Fifty-six of 130 students in the summer research program published one or more full-text manuscripts (43\%), and 77 of the students yielded one or more abstracts (59\%) (Figures 2A, 2B). The 61 published manuscripts had 79 student authors, and the 113

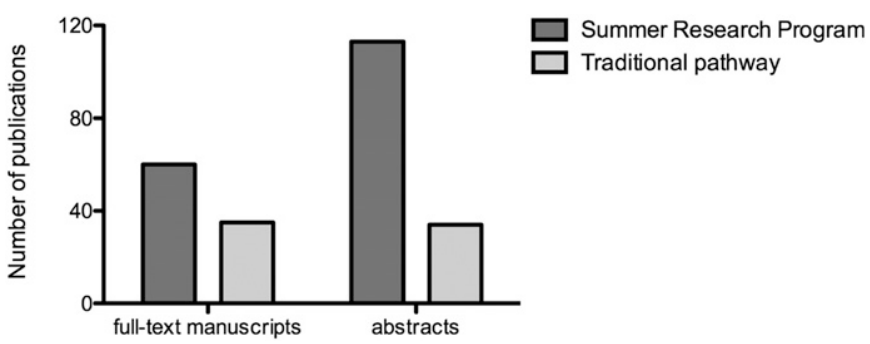

Figure 1. Total number of full-text publications or abstracts resulting from the summer research program or the traditional pathway to fulfill the research obligation.

podium or poster presentations had 154 student authors. Students who conducted their research at any time during the curriculum (not as part of the optional summer research program) yielded a total of 69 publications (35 full-text manuscripts and 34 abstracts; Figure 1). Fortysix of the 305 students published one or more full-text manuscripts $(15 \%)$ and 48 published one or more abstracts $(16 \%)$ (Figures $2 \mathrm{~A}$ and $2 \mathrm{~B})$. For the standard research project, the 35 published manuscripts had 51 student authors and the 34 podium or poster presentations had 73 student authors. The comparisons between students in the summer research program and in the required research project regarding the number of students with one or more full-text/abstract publications and the percentage of students with one or more full-text/abstract publications were all statistically significant, $p<0.001$.

Fifty-seven of 61 (93\%) of all full-text publications from the summer research program and 30 of 35 (86\%) of all full-text publications resulting from the standard research project were indexed in PubMed. Full-text manuscripts not indexed in PubMed included one book chapter and publications in Drug Topics, California Pharmacist, Hospital Pharmacy, Current Topics in Virology,

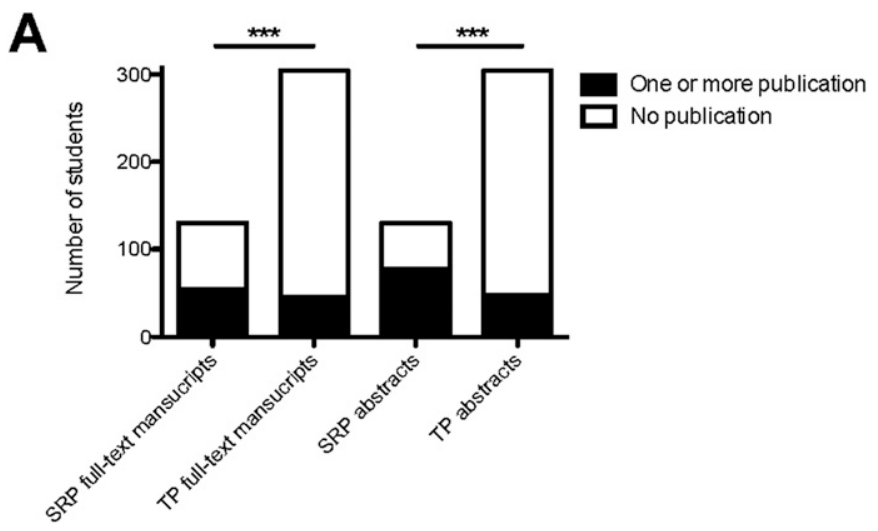

Figure 2A. Absolute number of students with one or more fulltext publications or abstracts participating in the summer research program (SRP) or the traditional pathway (TP) to fulfill the research obligation. ${ }^{* * *} p<.0001$, two-tailed Fisher's exact test. 


\section{American Journal of Pharmaceutical Education 2017; 81 (3) Article 48.}

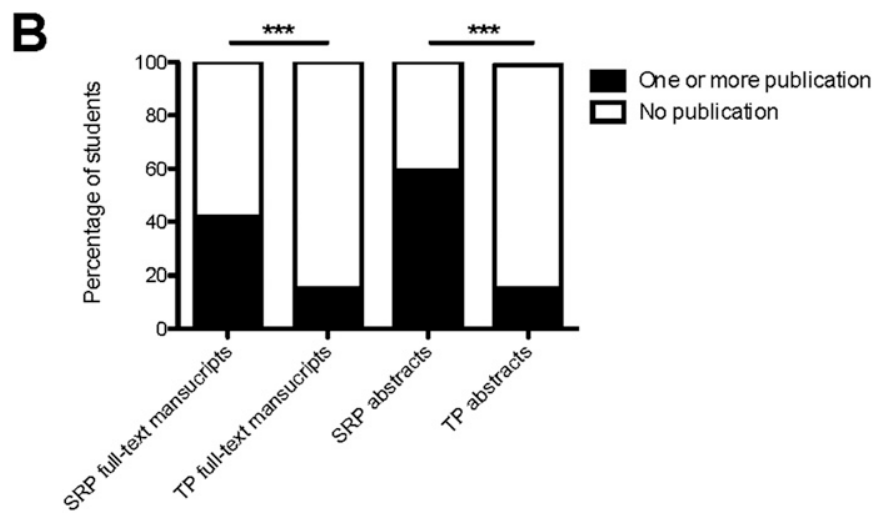

Figure 2B. Percentage of students with one or more full-text publications or abstracts participating in the summer research program (SRP) or the traditional pathway (TP) to fulfill the research obligation. $* * * p<.0001, Z$-test.

California Journal of Health-System Pharmacy, European Journal for Person Centered Healthcare and the American Journal of Pharmacology and Toxicology. The 87 full-text manuscripts indexed in PubMed were published in 53 different journals. Most of the journals were not pharmacy organization-specific journals; the most common journals in which students published were the Journal of Analytical Toxicology (16 publications), Journal of Opioid Management (4 publications), AIDS (3 publications) and the Annals of Pharmacotherapy (3 publications).
Along with the contribution of a required research project to scholarly activity, another important outcome is the students' satisfaction. Questionnaires were analyzed from students graduating in 2014 and in 2015, with 60 students participating in the summer research program, and 54 students completing the standard research project. Of 114 students, 105 returned their questionnaire, yielding a response rate of $92 \%$. Students generally expressed positive perceptions of the research project in either track and provided favorable responses. No significant differences between the summer research program and the traditional track were found in the provided statements concerning the overall evaluation of the project, the project adviser, or the topic of the research project or implications for their future career (Table 1). The highest overall rating ( $>4.7$ on a 5 point Likert scale) in both pathways was received for statements related to the selection of the topic, the selection of the adviser and for the overall valuable learning experience.

\section{DISCUSSION}

This study indicates that establishing a dedicated 12-week research experience during the summer after year one or year two in pharmacy school resulted in significantly more publications compared to research performed at any time during the curriculum. Notably, the publications were distributed across 63 different journals/ books, demonstrating an impact not just within the

Table 1. Student Perceptions of the Summer Research Program $(n=57)$ and the Traditional Pathway to Fulfill the Required Research Project $(n=48)$ in 2014-2015

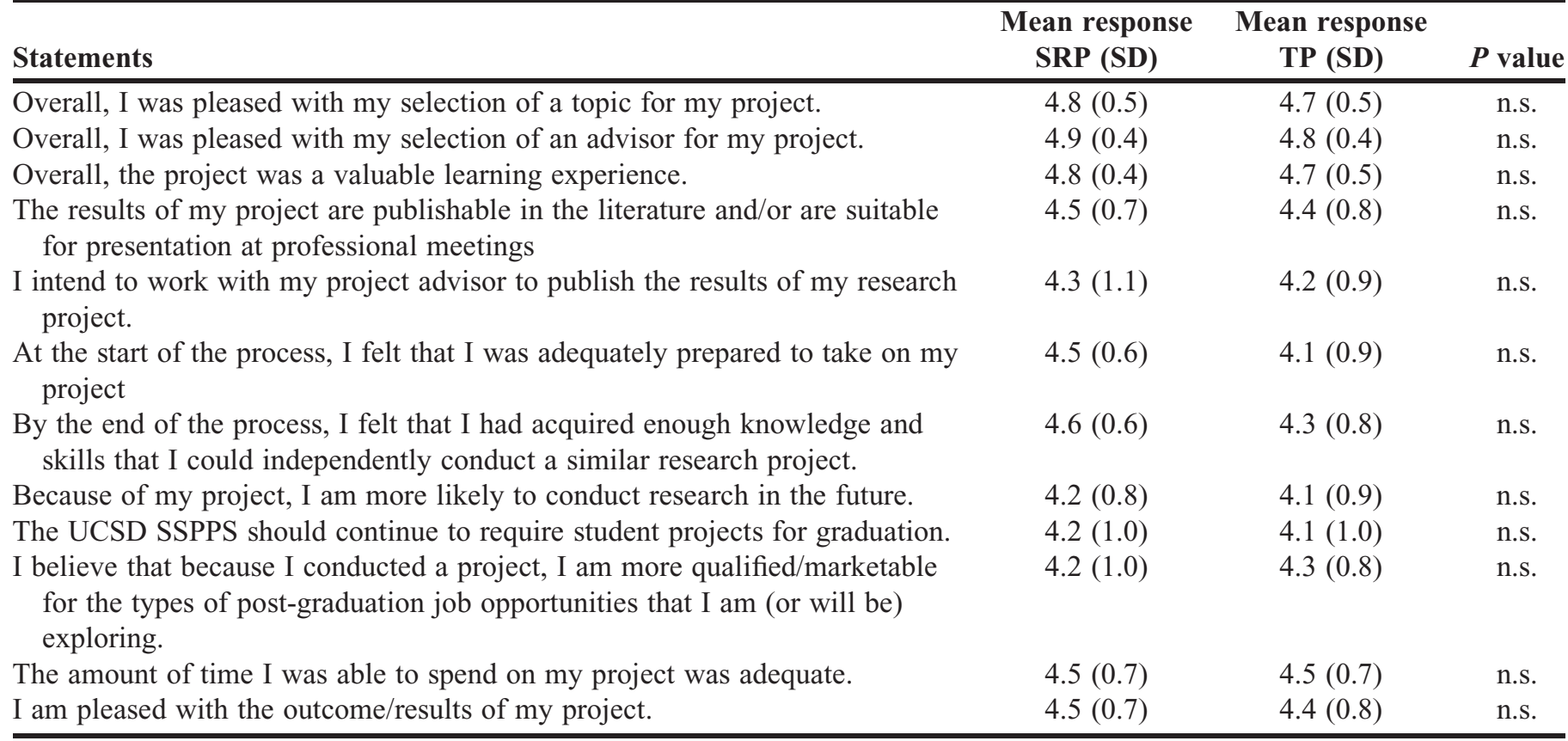

Likert scale 1-5; 1 = strongly disagree, 2 = disagree, $3=$ neutral, $4=$ agree, $5=$ strongly agree; Summer Research Program (SRP), traditional pathway (TP); n.s. $p>.05$, Mann-Whitney $U$ test 


\section{American Journal of Pharmaceutical Education 2017; 81 (3) Article 48.}

pharmacy profession but also across various biomedical specialty fields.

Several pharmacy schools have appreciated the general value of a required research project, and more pharmacy schools are implementing research programs into their curricula. ${ }^{5}$ However, reports on the successful performance are sparse and, therefore, research-related outcomes are rarely described. Recent studies mostly rely on satisfaction measures ${ }^{7,8,10-15}$ to assess the training effectiveness with only a few studies analyzing the publication rate as one measure of success. ${ }^{7,10,11}$ Previous experiences in PharmD curricula show publication rates between $5.3 \%$ and $28.8 \%$ for full-text manuscripts, and between $27 \%$ and $42.3 \%$ for abstracts (including oral and poster presentations at regional/national meetings). ${ }^{7,10,11}$ Studies in medical schools reported publication rates between $5 \%$ and $41 \%$ for full-text publications, and $22 \%$ and $55 \%$ for abstracts. ${ }^{16-19}$ Our own publication rate of $15 \%$ (for one or more full-text manuscripts) for the required research project through the traditional pathway is in line with previous reports. The lower publication rate of abstracts might reflect the more stringent definition of abstract used in this study. As a poster presentation at an institutional forum is a requirement for graduation, only abstracts from national and international meetings were considered for this study. Other studies often included presentations at regional/institutional forums in their analyses.

The implementation of a summer research program significantly increased the publication rate and exceeds the rates of our standard research project and also that reported from other institutions. ${ }^{7,10,11}$ Although the publication rate is only one measure of academic success, students and faculty both benefit from the high publication rate. Therefore, a dedicated time frame of 12 weeks to work full-time on the project seems an important predictor for academic success in this area. Several factors contribute to the success of a summer research program. A student who commits his or her summer to do full-time research is not allowed to accept other obligations such as collecting large numbers of intern hours or elective credits and can therefore fully concentrate on the research project. Further, the stipend support for living expenses is critically important, allowing the student to focus on the research full-time instead of working a full- or close to full-time job over the summer. Also, as research projects are always prone to failure, immediate adaption, modification, and changes in certain aspects of the project can take place without any further delay to guarantee successful completion of the study within the dedicated timeframe. It is also an advantage for the mentor to work with a student full-time. Frequent mentoring and available mentors enable implementation of a successful "initiation stage" for an effective mentor-protégé relationship. ${ }^{20}$

As discussed in the introduction, the implementation of a hands-on research project provides several advantages. Another benefit of a research program is to identify and stimulate students with the greatest potential for research careers and to increase the pool of capable biomedical researchers within this population. ${ }^{10,21}$ Although the PharmD degree offers unique perspectives to the biomedical research enterprise, PharmD investigators who receive competitive funding are relatively scarce. Recent studies have shown that a hands-on research project increases self-efficacy, ${ }^{22}$ stimulates scholarly activity, and increases the likelihood a student will conduct research in the future. ${ }^{12}$ SSPPS offers a combined PharmD/PhD program available to all enrolled PharmD students. A hands-on research project may foster interest among PharmD students in pursuing this dual degree program. ${ }^{23}$

Additionally, PharmD graduates with some research background are in an excellent position to apply and compete for various positions in the pharmaceutical industry. With the current advances and changes in health care models and the scope of practice of pharmacists, an important goal for training future pharmacists is to ensure they will be competitive in alternative career pathways on the job market. A research program within the PharmD curriculum may help prepare students to compete successfully for positions throughout the pharmaceutical industry.

Implementing a required research project into a PharmD curriculum is institutionally challenging and requires faculty time and resources for stipend support and research materials. Funding is certainly the most challenging part given the limited possibilities to apply for funds paying short-term research positions for pharmacy students. The initial opportunity for pharmacy students at SSPPS to perform stipend-supported summer research arose in the summer of 2006 from an NIH Roadmap Initiative T32 Predoctoral Clinical Research Training Program in the UC San Diego School of Medicine. In addition to the long-term training positions, this grant provided short-term stipends for selected UC San Diego medical and pharmacy students to conduct clinical research projects, and supported seven pharmacy students in that first summer. This was followed by a TL1 training grant that funded three to seven students each summer, and a T35 training grant that has supported five trainees each summer since 2010.

The stipends for the remainder of the students have come from a variety of sources actively solicited throughout the year, including successful partnerships with local 


\section{American Journal of Pharmaceutical Education 2017; 81 (3) Article 48.}

industry, individual faculty NIH grants, foundation and industry grants, and SSPPS internal funds for student scholarships and fellowships. This provides a model for the combination of funding sources that could be used to support such a program.

Another critical component is finding equally engaged, motivated, and well-trained faculty to serve as mentors for pharmacy students. Sometimes we find highly engaged mentors who are not fully familiarized with certain research methods. It is helpful to pair them with another faculty member who can help with supervising the correct research methods. Another challenge can be interpersonal communication problems between the mentor and the mentee. We found it helpful to provide regular meetings for all summer research project students to gather with the summer research project director. Interpersonal problems that arise between the mentor and the trainee can be addressed during these meeting times.

This study has several limitations. First, the data have been collected in a single pharmacy school with a researchintensive environment within and adjacent to campus. Research projects are therefore generally more feasible as trained faculties and numerous projects are readily available. Also, the type of student inclined to participate in the summer research program might influence the high publication rate. Students who choose to do their research requirement over the summer break might be self-selected as those with a higher motivation to successfully complete the research project during the summer. Another limitation of the study is the search strategy to assess the publication rate. Although the search strategy was standardized, there is always a risk of missing information as names of students or preceptors can change (eg, marriage).

For students conducting their research at any time during the curriculum, thus also in the third and fourth years, it is conceivable that publications resulting from this work occurred after they graduated. Therefore, the search of Google and PubMed may not have picked up publications of students who did their research particularly in the last two years of this study (graduating class of 2014 and 2015). This would cause a bias in favor of publications in the summer research program. Also, students in the traditional research project track often work in groups of up to four students, while the summer research program funds one student per project. It is conceivable that "solo students" take more ownership of a project than does a group and might be more motivated to publish their own work. In addition, the minimum time commitment for the two research pathways is different, although the actual total time spent on the research project in both pathways differs from project to project and often exceeds the minimum requirement by many times.
The determination of publication rates and the impact on students' satisfaction are limited criteria for assessing the effectiveness of research training. The ultimate goal for establishing a research program within a PharmD curriculum is to foster an appreciation of evidence-based health care and a desire to contribute to the biomedical research enterprise in the future. Therefore, as a future direction, post-graduate impact and the overall effect on the profession of pharmacy need to be determined. Surveying graduates from the summer research program and determining their career pathway and ongoing contribution to biomedical research should be used to assess the long-term outcomes of the summer research program.

\section{CONCLUSION}

A dedicated, stipend-supported, 12-week summer research program for first- and second-year pharmacy students was highly valued by the students and mentors and led to a significant increase in publications compared to the standard required research project. Investment of NIH, industry, and institutional resources supported the growth of this optional program. Our study should encourage other institutions to implement, support, and further refine a student-driven research project in a PharmD curriculum.

\section{ACKNOWLEDGMENTS}

The authors wish to thank the NIH funding agencies of the following grants for providing support to pharmacy students to participate in short-term research projects: 5T32RR023254, PI Dr. Carolyn Kelly; 5T35HD064385, MPIs Drs. Brookie Best and Palmer Taylor; 5T32MH019934, PI Dr. Dilip Jeste; 1TL1TR001443, PIs Dr. Colin Depp and Carolyn Kelly. The authors also wish to thank Dr. James McKerrow for his continued strong investment in and support of our students participating in the summer research program. We thank our past and current industry partners for their support and collaboration, including Ardea Biosciences, Millennium Research Institute, and Human Longevity Institute. We acknowledge the critically important contributions of the current directors of the summer research program (Dr. Joseph Ma) and the required research project (Dr. Felix Yam). Finally, we gratefully acknowledge all of the excellent mentors who provide and support these enriching research experiences for our students.

\section{REFERENCES}

1. Accreditation standards and key elements for the professional program in pharmacy leading to the doctor of pharmacy degree. Standards 2016. Chicago, IL. Feb 2, 2015.

2. Murphy JE, Peralta LS, Kirking DM. Research experiences and research-related coursework in the education of doctors of pharmacy. Pharmacotherapy. 1999;19(2):213-220. 


\section{American Journal of Pharmaceutical Education 2017; 81 (3) Article 48.}

3. Murphy JE, Slack MK, Boesen KP, Kirking DM. Research-related coursework and research experiences in doctor of pharmacy programs. Am J Pharm Educ. 2007;71(6):Article 113.

4. Ascione FJ. Research requirement for PharmD students. Am J Pharm Educ. 2007;71(6):Article 115.

5. Fuji KT, Galt KA. Research skills training for the doctor of pharmacy in US schools of pharmacy: a descriptive study. Int $J$ Pharm Pract. 2009;17(2):115-121.

6. Bloom BS. Taxonomy of Educational Objectives: Cognitive Domain. New York, NY. David McKay Co., Inc.; 1956.

7. Assemi M, Ibarra F, Mallios R, Corelli RL. Scholarly contributions of required senior research projects in a doctor of pharmacy curriculum. Am J Pharm Educ. 2015;79(2):Article 23.

8. Vaidean GD, Vansal SS, Moore RJ, Feldman S. Student scientific inquiry in the core curriculum. Am J Pharm Educ. 2013;77(8):Article 176. 9. Bierer SB, Chen HC. How to measure success: the impact of scholarly concentrations on students - a literature review. Acad Med. 2010;85(3):438-452.

10. Johnson JA, Moore MJ, Shin J, Frye RF. A summer research training program to foster PharmD students' interest in research. Am J Pharm Educ. 2008;72(2):Article 23.

11. Kao DJ, Hudmon KS, Corelli RL. Evaluation of a required senior research project in a doctor of pharmacy curriculum. Am J Pharm Educ. 2011;75(1):Article 5.

12. Kim SE, Whittington JI, Nguyen LM, Ambrose PJ, Corelli RL. Pharmacy students' perceptions of a required senior research project. Am J Pharm Educ. 2010;74(10):Article 190.

13. Nykamp D, Murphy JE, Marshall LL, Bell A. Pharmacy

students' participation in a research experience culminating in journal publication. Am J Pharm Educ. 2010;74(3):Article 47.
14. Vaidean GD, Vansal SS, Moore RJ, Feldman S. Student scientific inquiry in the core doctor of pharmacy curriculum: critical issues in designing and implementing a student research program. Innov Pharm. 2013;4(131):1-15.

15. Wuller CA. A capstone advanced pharmacy practice experience in research. Am J Pharm Educ. 2010;74(10):Article 180.

16. Burge SK, Hill JH. The medical student summer research program in family medicine. Fam Med. 2014;46(1):45-48.

17. Dyrbye LN, Davidson LW, Cook DA. Publications and presentations resulting from required research by students at Mayo Medical School, 1976-2003. Acad Med. 2008;83(6):604-610.

18. Rhyne RL. A scholarly research requirement for medical students: the ultimate problem-based learning experience. Acad Med. 2000;75(5):523-524.

19. Smith FG, Harasym PH, Mandin H, Lorscheider FL. Development and evaluation of a research project program for medical students at the University of Calgary faculty of medicine. Acad Med. 2001;76(2):189-194.

20. Haines ST. The mentor-protégé relationship. Am J Pharm Educ. 2003;67(3):Article 82.

21. Figg WD, Chau $\mathrm{CH}$, Okita $\mathrm{R}$, et al. PharmD pathways to biomedical research: the National Institutes of Health special conference on pharmacy research. Pharmacotherapy. 2008;28(7): 821-833.

22. Black ML, Curran MC, Golshan S, et al. Summer research training for medical students: impact on research self-efficacy. Clin Transl Sci. 2013;6(6):487-489.

23. Gourley DR, Rowell C, Wingate L, et al. Status of PharmD/ $\mathrm{PhD}$ programs in colleges of pharmacy: the University of Tennessee dual PharmD/PhD program. Am J Pharm Educ. 2006; 70(2): Article 44. 